\title{
A Review of Dreamland: The true tale of America's opiate epidemic by Sam Quinones
}

\author{
Bloomsbury Press, 2016, 386 pages \\ ISBN: 9781620402504
}

\author{
Julia Kay Wolf \\ West Virginia University, Morgantown, WV, USA \\ ¡kwolf@mix.wvu.edu
}

Authored by Sam Quinones, Dreamland: The True Tale of America's Opiate Epidemic, is a timely and well-researched account of the insidiousness of the opiate epidemic that is ravaging the United States. Silently beginning in the 1980s, but only recently garnering national attention, heroin and prescription opiates made their way across America and disproportionately devastated rural areas. Case and Deaton (2015), though not the first to notice startling trends in drug-related mortality, grabbed academia's attention with their startling coverage of rising death rates of middle-aged white non-Hispanic men and women over the course of 1999 to 2013. Upon closer inspection, they found it was "largely accounted for by increasing death rates from drug and alcohol poisonings, suicide, and chronic liver diseases and cirrhosis" (Case and Deaton 2015:1), later deeming them "deaths of despair" (Case and Deaton 2017:2). Concurrently, increased social media attention to many overdose deaths from opiates, especially in Ohio and West Virginia, brought the issue to the forefront of the public eye. Tension grew in both the professional and public spheres regarding appropriate treatment for those who have overdosed and left many wondering why these increases in deaths were happening in the first place. In this book, journalist Sam Quinones explores the complex stream of events leading to these developments that have culminated in a public health emergency.

Quinones takes the reader through the interwoven history of scientific breakthroughs and failures, economic decline, ingenious unethical marketing practices laced with greed, efforts to obtain the "American Dream," and the dismal catastrophic outcome. He immediately grabs the reader's interest by painting an idyllic picture of what once was "Dreamland" - Portsmouth, Ohio. In the early 1900s, this "industrial town in the rural heartland" was the perfect place to raise a family and connect with neighbors (p. 24). Regrettably, it faced economic decline and job losses along with the rest of the American Rust Belt in the 1970s, and became an abandoned shell of what it once was. It was in Portsmouth and nearby South Shore, Kentucky where a covetous and predatory doctor, initially trying to treat a growing number of residents for disability or workers' compensation, established what would become one of the first pill mills in the Ohio River Valley in the mid-1980s. Quinones starts his narrative here to vividly illustrate 
the economic success and decline in rural America that set the scene for the rampant proliferation of drugs.

Nevertheless, he points out that declining economic conditions were only one piece of the long-term puzzle that led to the opiate epidemic. A new revolution was taking over the medical and scientific community - curing a patient's pain was now a top priority. In the 1980s pain specialists pushed doctors to address this difficult to measure component of health; however, despite the good intentions behind this crusade, its tenacity fell victim to faulty science. Quinones delves into the shoddy research that pushed opiates as the cure-all pills, and he does not hold back exposing the role of Purdue Pharma's corporate greed in pushing it to increase sales of its new continuous release opiate pill-OxyContin. In response, he deftly highlights the ebb and flow of holistic pain management techniques and supports their growing resurgence.

While skillfully blending fields of health, marketing, medicine, sociology, and economics, Quinones also covers several criminal components bolstering the opiate epidemic. On the other side of the country, a new drug - black tar heroin - and the dealers' innovative delivery system were thriving. He discusses interviews with various police officers, prosecutors, and federal agents who had slowly become aware of a new method of heroin dispersal in previously unaffected areas. Tracking the deliveries of this potent drug to a small state in Mexico called Nayarit, Quinones not only discusses the seemingly unending supply of willing workers, but also elaborates on the economic conditions of this impoverished place that is reminiscent of Portsmouth.

Without diminishing the terrible effects of their actions, Quinones is still able to empathetically portray several of the illegal drug dealers in the social and economic contexts they live - typically teenagers who are working to help themselves and their family. In doing so, a larger picture of troublesome economic conditions and double standards emerges. Though Quinones does not use Marxist terms, criminologists can see a glaring example of members of the ruling class (i.e., Purdue Pharma executives) benefiting from their position while members of a subordinate class (i.e., heroin deliverers) are criminalized for an incredibly similar operation. Related to this point, Quinones notes that Purdue Pharma was eventually convicted of one felony count of "misbranding" and executives were punished via fines, probation, and community service for their role in the deaths of thousands, but many heroin dealers were sentenced to prison and were unable to buy their way out. These outcomes show the power imbalance between those who own the means of production and those who do not.

Location was a critical factor in the implementation and the continuation of the heroin and OxyContin epidemic - hitting rural areas disproportionately severely. Quinones highlights the insidiousness of the opiate epidemic by contrasting its silent development in Appalachia and rural America and its initially quiet spread across the country with the blatant violence of the prior cocaine and methamphetamines epidemics. Walmart, a rural corporate giant, became vital 
for those in the illegal OxyContin market as shoplifted items were used to exchange for pills. One surprisingly positive consequence of growing drug use in these typically conservative rural areas was that since those who were becoming addicted now (i.e., white, upper- and middleclass) tended to have relationships with those in seats of power, legislators began shifting towards advocating drug courts instead of prison.

From Portsmouth, $\mathrm{OH}$ to Portland, OR and the surrounding rural areas, the opiate epidemic has been a rural criminological phenomenon. It encompasses corporate crime, criminal activity, and the interaction between the two - especially prominent in rural and suburban areas that had not seen this kind of drug activity before. New marketing techniques from both Purdue Pharma and Nayarit (more specifically, Xalisco) were stunning with their intricacy and efficiency; the heroin cells in particular were completely new to police and federal agents who had dealt with drug trafficking for decades. However, Quinones must be applauded for not only focusing on the criminal aspects, but also the health and sociological perspective in which he frames this perfect storm. He explains not only how such a harmful drug basically removes the possibility of making choices from the individual, but also the economic conditions that fed into the sense of despair in the first place - thus garnering a more empathetic insight to their problems. He also shows how important epidemiologists and health personnel were to discovering the new epidemic as well as how important accurate data is to continually monitor changing situations. Finally, he advocates for a "bio-psycho-social approach" for dealing with such complex issues contributing to pain ( $p$. 87). Comprehensive care is critical for truly dealing with pain, not just pills.

Quinones' journalistic approach, greatly akin to an ethnographic study, provides a highly intelligible account of the seemingly disparate historical events that contributed to the opiate epidemic. As such, he does not delve deeper into theoretical considerations of criminal law (e.g., Marxist theories) common in academic work, but rather draws parallels in ways the lay reader can understand. He turns the opiate epidemic from a black and white description of "evil" drug users and dealers and "good" doctors and companies to a greyscale of individuals and families who are trying to deal with failing local economies with instances of corruption throughout. His thorough historical account of America's opiate epidemic, particularly robust in rural and suburban areas, provides a clear picture of how greed, poor economic conditions, and despair can lead people to crime and offers solutions via comprehensive approaches targeting more than just drugs. Public health officials, academic researchers, police, federal agents, and community members affected by the opiate epidemic can benefit from reading this book and gaining insight into how this problem emerged and find some helpful, long-term suggestions for ending it. 


\section{References}

Case, A., \& Deaton, A. (2017). "Mortality and morbidity in the 21st century." Brookings Papers on Economic Activity, 397-476. https://doi.org/10.1353/eca.2017.0005

Case, A., \& Deaton, A. (2015). "Rising morbidity and mortality in midlife among white nonHispanic Americans in the 21st century." Proceedings of the National Academy of Sciences, 112(49), 15078-83. https://doi.org/10.1073/pnas.1518393112

Quinones, S. (2016). Dreamland: The true tale of America's opiate epidemic. New York, NY: Bloomsbury Press. 